\title{
Symmetry breaking of the cellular lobes closely relates to phylogenetic structure within green microalgae of the Micrasterias lineage (Zygnematophyceae)
}

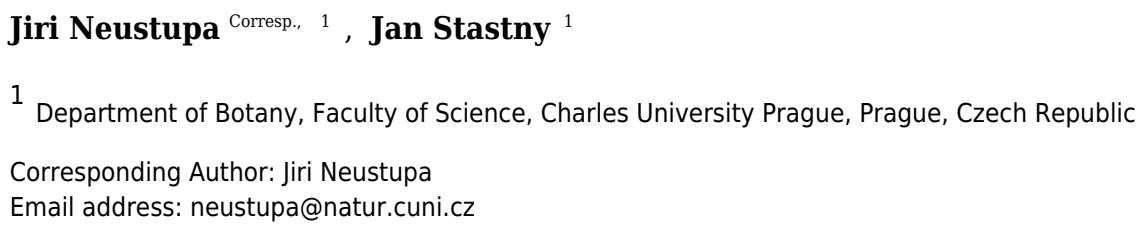

Green microalgae of the Micrasterias lineage are unicellular microorganisms with modular morphology consisting of successively differentiated lobes. Due to their morphological diversity and peculiar morphogenesis, these species are important model systems for studies of cytomorphogenesis and cellular plasticity. Interestingly, phylogenetic structure of the Micrasterias lineage and most other Desmidiales is poorly related to the traditional morphological characters used for delimitation of taxa. In this study, we focused on symmetry breaking between adjacent cellular lobes in relation to phylogeny of the studied species. While pronounced morphological asymmetry between the adjacent lobes is typical for some species, others have been characterized by the almost identical morphologies of these structures. We asked whether there is any detectable average shape asymmetry between the pairs of lobes and terminal lobules in 19 Micrasterias species representing all major clades of this desmidiacean lineage. Then, we evaluated whether the asymmetric patterns among species are phylogenetically structured. The analyses showed that the phylogeny was in fact strongly related to the patterns of morphological asymmetry between the adjacent cellular lobes. Thus, evolution of the asymmetric development between the adjacent lobes proved to be the key event differentiating cellular shape patterns of Micrasterias. Conversely, the phylogeny was only weakly related to asymmetry between the pairs of terminal lobules. The subsequent analyses of the phylogenetic morphological integration showed that individual hierarchical levels of cellular morphology were only weakly coordinated with regard to asymmetric variation among species. This finding indicates that evolutionary differentiation of morphogenetic processes leading to symmetry breaking may be relatively independent at different branching levels. Such modularity is probably the key to the evolvability of cellular shapes, leading to the extraordinary morphological diversity of these intriguing microalgae. 


\section{Symmetry breaking of the cellular lobes closely relates to}

2 phylogenetic structure within green microalgae of the

3 Micrasterias lineage (Zygnematophyceae)

4

5 Jiri Neustupa ${ }^{1}$, Jan Stastny ${ }^{1}$

$6{ }^{1}$ Department of Botany, Faculty of Science, Charles University, Prague, Czech Republic

7

8 Corresponding Author:

9 Jiř́ Neustupa ${ }^{1}$

10 Benatska 2, Prague, 128 01, Czech Republic

11 Email address: neustupa@,natur.cuni.cz

12

13

14

15

16

17

18

19

20

21

22

23

24

25

26

27

28

29

30

31

32 


\section{Abstract}

34 Green microalgae of the Micrasterias lineage are unicellular microorganisms with modular morphology consisting of successively differentiated lobes. Due to their morphological diversity and peculiar morphogenesis, these species are important model systems for studies of

37 cytomorphogenesis and cellular plasticity. Interestingly, phylogenetic structure of the

38 Micrasterias lineage and most other Desmidiales is poorly related to the traditional

39 morphological characters used for delimitation of taxa. In this study, we focused on symmetry

40 breaking between adjacent cellular lobes in relation to phylogeny of the studied species. While

41 pronounced morphological asymmetry between the adjacent lobes is typical for some species,

42 others have been characterized by the almost identical morphologies of these structures. We

43 asked whether there is any detectable average shape asymmetry between the pairs of lobes and terminal lobules in 19 Micrasterias species representing all major clades of this desmidiacean lineage. Then, we evaluated whether the asymmetric patterns among species are phylogenetically structured. The analyses showed that the phylogeny was in fact strongly related to the patterns of

47 morphological asymmetry between the adjacent cellular lobes. Thus, evolution of the asymmetric development between the adjacent lobes proved to be the key event differentiating cellular shape patterns of Micrasterias. Conversely, the phylogeny was only weakly related to asymmetry between the pairs of terminal lobules. The subsequent analyses of the phylogenetic morphological integration showed that individual hierarchical levels of cellular morphology were only weakly coordinated with regard to asymmetric variation among species. This finding indicates that evolutionary differentiation of morphogenetic processes leading to symmetry breaking may be relatively independent at different branching levels. Such modularity is probably the key to the evolvability of cellular shapes, leading to the extraordinary morphological diversity of these intriguing microalgae. 
58

59

60

61

62

63

64

65

66

67

\section{Introduction}

The green algal genus Micrasterias (Desmidiales, Zygnematophyceae) is typical by uniquely elaborate cellular shapes with multiple incisions dissecting the cells into multiple lobes and lobules that compose their biradially symmetric morphologies (Prescott et al., 1977; Coesel \& Meesters, 2007). The arrangement and shapes of these morphological features are usually species specific; therefore, individual cells can be reliably identified by their cellular morphology. In contrast, clades of species as resolved by molecular phylogenies cannot be clearly defined by the shared morphological features ( ̌̌kaloud et al., 2011).

Previous studies showed that the Micrasterias lineage of Desmidiales consists of at least eight monophyletic clades, including one comprising species of the morphologically divergent traditional genus Triploceras (Hall et al., 2008; Gontcharov \& Melkonian, 2011; Škaloud et al., 2011). These clades do not unambiguously correspond to any of the formerly created infrageneric taxonomic units. Therefore, these clades have been informally assigned as A-H (Škaloud et al., 2011). In a prior study, Neustupa \& Stastny (2006) illustrated that phenetic trees based on morphological and morphometric features of different Micrasterias species are considerably different from phylogenetic structure. Neither the shapes of the cellular polar lobes, emphasized in traditional taxonomy (Prescott et al., 1977; Růžička, 1981), nor the quotient of isoperimetric inequality that quantifies the deviation of the cellular shapes from circular outlines correlate with the molecular phylogeny of Micrasterias (Škaloud et al., 2011). In contrast, it has been shown that the degree of cellular branching is basically the only phenotypic feature with a significant phylogenetic signal across the Micrasterias lineage (Škaloud et al., 2011). It is known that this feature is closely related to the cell size and nuclear genome size of individual species (Poulíčková et al., 2014; Neustupa, 2016), which suggests that, unlike the previously studied 
82 shape features, the sizes of the cells are actually constrained by the phylogenetic history of these

83 microalgae. However, the lack of size-unrelated characters correlated with the Micrasterias

84 phylogeny implies that the principal morphogenetic patterns underlying the evolutionary

85 diversification of this important model group for the study of cellular morphogenesis in

86 eukaryotic microorganisms (Kiermayer, 1970; Meindl, 1993; Lütz-Meindl, 2016) remain

87 unknown. Identification of phylogenetically conserved aspects of variation would indicate the

88 evolutionary developmental patterns that drive the phenotypic evolution of this lineage with

89 possibly the most complex cellular shapes among plants.

90 Micrasterias cells are bilaterally symmetric around multiple axes running through surface

91 incisions; these separate the cell into cellular halves (semicells), semicels into lateral lobes and

92 lateral lobes into successively branched lobules (Fig. 1A). The symmetry of these structures is

93 set up in cellular morphogenetic processes during semicell development following the asexual

94 mitotic cell division. Classical studies of Kiermayer $(1964 ; 1981)$ illustrated that the plasma

95 membrane of the developing semicell contains the "membrane recognition areas" for the vesicles

96 with the wall material formed in the Golgi apparatus and transported by actin microfilaments to

97 actively growing areas (Holzinger \& Lütz-Meindl, 2001; Holzinger et al., 2002). Apparently, the

98 position of the membrane recognition sites is genetically fixed, which is demonstrated by

99 species-specific differences in the symmetric morphologies of individual species of the lineage.

100 Kiermayer (1981) showed that while the surfaces of the developing semicells cease to extend

101 during the experimental turgor reduction, the primary wall material continues to accumulate

102 beneath the membrane, exactly reflecting the species-specific morphological pattern, i.e., the

103 positions and sizes of individual lobes and incisions. In normally developing semicells,

104 morphogenesis proceeds via a repeated spatiotemporal sequence consisting of discontinuation of 
105 primary wall growth at symmetrically arranged areas of the plasma membrane. These areas later

106 become incisions, and the parts that continue to grow by tip elongation develop into lobules.

107 Unlike in moss protonemata or in pollen tubes of vascular plants, tip growth of the lobules is

108 multipolar, occurring simultaneously in different parts of a developing semicell (Kiermayer \&

109 Meindl, 1989; Holloway \& Harrison, 1999; Lütz-Meindl, 2016). The genome-wide transcript

110 profiling in $M$. denticulata showed that this tip growth phase is related to expression of expansin-

111 like proteins similar to those involved in the cell morphogenesis of land plants (Vannerum et al.,

112 2011).

113 However, in addition to multiple morphological symmetries, the cells of Micrasterias also

114 typically include different levels of asymmetry. The development of opposite semicells is often

115 separated by considerable time lags, implying that changes in environmental factors that affect

116 morphogenetic processes, such as the external temperature (Meindl, 1990; Neustupa et al.,

117 2008), may lead to pronounced morphological differences between two opposite mature

118 semicells forming a single cell. Simultaneously, subtle but detectable asymmetry in shape was

119 detected between two lateral lobes of the same semicell (Savriama et al., 2010; Neustupa, 2017).

120 This asymmetry is supposedly a result of morphogenetic noise during synchronous development

121 of the semicell halves. It should be emphasized that both these asymmetric patterns of cellular

122 morphology are typical by their side ambiguity (Savriama et al., 2010; Neustupa, 2013) because,

123 unlike bilateral animals or leaves of vascular plants, the cells of green algae typically lack any

124 anterior-posterior differentiation (McManus et al., 2011; Lenarczyk \& McManus, 2016).

125 Therefore, the left and right sides of the frontal views of cells cannot be assigned and analyzed

126 among different individuals. Consequently, the analysis of asymmetric variations in the shapes of

127 the semicells or their lateral lobes cannot separate the side-directed, average asymmetry between 
128 two structures of an entire population (i.e., directional asymmetry (DA)) from individual

129 asymmetric deviations (i.e., fluctuating asymmetry (FA)).

130 However, complex morphology of Micrasterias cells includes additional structures within the

131 lateral lobes that are symmetric to each other and are differentiated based on their relative

132 positions. Each lateral lobe is typically split into two lateral sublobes, and in some species, these

133 sublobes can be further divided into higher-order terminal lobules. These lateral sublobes within

134 each lobe are bilaterally symmetric, and their side orientation can be assigned with respect to

135 their position within the lateral lobe (Fig. 1). From the perspective of phenotype evolution in the

136 Micrasterias lineage, the average asymmetry between adjacent pairs of the lateral sublobes in

137 individual species may be of special interest. Similar to other repeated symmetric parts of

138 organismal bodies, such as arthropod segments (Savriama et al., 2017), or cells in algal or

139 bacterial filaments (Graham et al., 2010), symmetry of the different segments may be broken by

140 different developmental signals specifying the position within the translational series. Thus, this

141 idea may also be used for quantification and comparison of average shape differences in

142 positional asymmetry, i.e. the symmetry breaking between adjacent sublobes within the

143 Micrasterias cells. It should be noted that this component of the asymmetry between the adjacent

144 sublobes basically corresponds to DA of the bilateral structures, such as animal body plans or

145 vascular plant leaves (Klingenberg et al., 2002). However, as it does not relate to any

146 directionally determined left-right asymmetric differences, we refrain from using the explicit

147 term DA for this positional asymmetry between the adjacent sublobes within the Micrasterias

148 cells.

149 Interestingly, positional component of asymmetry between the sublobes is probably

150 genetically fixed and typifies individual taxa. For example, the lateral sublobes of several 
151 Micrasterias species, such as M. rotata, M. fimbriata, and M. apiculata, are strongly asymmetric

152 (Coesel \& Meesters, 2007). Their lower lateral sublobe (LLS) is markedly compressed, and this

153 apparent positional asymmetry has been considered one of the basic features used for their

154 taxonomic definition (Rüžička, 1981). On the other hand, there are also a number of taxa, such as

155 M. americana, M. furcata, and M. thomasiana, with almost identical lateral sublobes (Prescott et

156 al., 1977; Růžička, 1981). Thus, Růžička (1981) described the lateral sublobes of M. thomasiana

157 as being "almost of the same width" and those of M. americana as being "approximately of the

158 same width". These species may either lack any significant positional asymmetry in the shapes of

159 the lateral sublobes, or it is subtle and is undetectable by qualitative microscopic observation.

160 However, such positional asymmetry could possibly be identified by a morphometric analysis of

161 the shape features of the adjacent sublobes in these Micrasterias species.

162 Studies of cellular morphogenesis have illustrated that the prominent positional asymmetry

163 between the lateral sublobes in $M$. rotata is already established in the early phases of

164 development in the asymmetric setting of the minimum accretion zones on the plasma membrane

165 of the developing semicell (Kiermayer, 1981; Lütz-Meindl, 2016). This leads to the development

166 of a considerably narrower and less segmented LLS in comparison to its upper lateral sublobe

167 (ULS) counterpart (Fig. 1). Detection of a similar pattern of positional asymmetry in shape of the

168 adjacent lateral sublobes in other species of the Micrasterias lineage would imply that this

169 feature is evolutionarily conserved and distributed throughout this phylogenetic lineage, and

170 individual species differ only in the degree of this asymmetry. Conversely, it is possible that

171 some species lack this type of asymmetry and that their average shapes of the LLSs and ULSs

172 are not significantly different. This result would indicate that the splitting of two membrane

173 parts, which precedes the development of the lateral sublobes, is truly dichotomic. This pattern 
174 was largely assumed by the mathematical models of cellular morphogenesis in Micrasterias

175 based on the two-morphogen reaction-diffusion activity, controlling the growth and branching of

176 the developing membrane parts within the growing semicell (Holloway \& Harrison, 2008;

177 Holloway, 2010). Finally, the analysis might show that significant positional asymmetry is

178 present in most or all of the studied species but that the patterns of this asymmetry are markedly

179 different among taxa. Thus, in this scenario, some species would not have the relatively more

180 compressed LLSs, typical for M. rotata or M. fimbriata, but would possibly exhibit a different

181 and significant pattern of positional asymmetry in the shape of the lateral sublobes. This result

182 would then lead to the question of how these different asymmetric patterns are related to the

183 evolutionary history of Micrasterias. By evaluation of these scenarios, we would like to illustrate

184 the way in which the cellular morphogenetic mechanisms leading to fixed asymmetry of

185 individual structures within the species-specific morphology may be related to evolutionary

186 history of the lineage and how this phenomenon can be reflected in the observed morphological

187 diversity of these unicellular organisms.

188 The lateral lobes of many Micrasterias species are successively differentiated into higher-

189 order lobules (Fig. 2). Recently, it was shown that shape variation of the adjacent terminal

190 lobules in M. compereana is tightly integrated (Neustupa, 2017). However, such high covariation

191 may not be present in the asymmetric variation of these lobules across species. If the patterns of

192 the among-species asymmetric variation prove to be tightly integrated among different levels of

193 cellular differentiation, then the morphogenetic mechanisms of symmetry breaking likely act

194 relatively uniformly during successive development of the lobes and their subordinate sublobes

195 and lobules. In species with pronounced positional asymmetry between the lateral sublobes, such

196 as M. rotata, this scenario would imply that similar asymmetric pattern is shared by adjacent 
197 pairs of sublobes. Likewise, species with relatively equal lateral sublobes would also exhibit

198 almost identical pairs of adjacent terminal lobules.

199 Alternatively, we may find that the dynamics of asymmetry among different levels of cellular

200 branching is unrelated among the species. This outcome would suggest that individual stages of

201 the morphogenetic process are relatively independent and evolved separately in different species.

202 This result would indicate minimal evolutionary coordination among the successive stages of

203 cellular development, which may facilitate the evolution of different shape patterns at individual

204 stages and may significantly contribute to the observed morphological diversity of these

205 organisms.

206 In summary, the present study evaluates the following specific questions:

207 1) What are the patterns of positional asymmetry in the shapes of the lateral sublobes of

208 Micrasterias species? Are these asymmetric patterns related to the phylogenetic relationships

209 among the species?

2102 2) Is the species-level positional asymmetry in the shapes of the lateral sublobes also shared

211 by the pairs of $2^{\text {nd }}$-order sublobes within the ULS and LLS, indicating homogenous

212 morphogenetic mechanisms of symmetry breaking across successive levels of cellular

213 development? In other words, is there a significant phylogenetic morphological covariation in

214 asymmetric variation between different levels of cellular lobes?

215 These questions were answered by performing geometric morphometric analyses of the

216 cellular shapes of 19 Micrasterias species. The answers to these questions should help us

217 describe the evolutionary diversification of morphogenetic patterns, which lead to specific

218 morphologies of individual taxa and are reflected in the observed diversity of the extant taxa. 
220

221

222

223

224

225

226

227

228

229

230

231

232

233

234

235

236

237

238

239

240

241

242

\section{Material \& Methods}

\section{Sampling, cultivation and data acquisition}

The data were based on populations of 19 Micrasterias taxa (Fig. 2, Table S1) representing all major phylogenetic clades of this desmidiacean lineage as previously recovered by Škaloud et al. (2011). The samples from the natural communities were immediately fixed by using Lugol's solution and stored in the dark at $17^{\circ} \mathrm{C}$. The strains were cultured in MES-buffered DY IV liquid medium at $23{ }^{\circ} \mathrm{C}$ and illuminated at $40 \mu \mathrm{mol}$ photons $\mathrm{m}^{-2} \mathrm{~s}^{-1}$ with LED EVOLVEO natural light $9 \mathrm{~W}$ bulbs under a light:dark (L:D) regime of 12:12 h. Notably, 5 of the studied taxa have been treated as subspecies in traditional taxonomic monographs (Růžička, 1981). However, published phylogenetic data clearly illustrated that these taxa form well-delimited species-level evolutionary units within the genus Micrasterias (Nemjová et al., 2011; Škaloud et al., 2011; Neustupa et al., 2014). Therefore, in our analses we treated these taxa as separate units.

For each taxon, a total of 75 mature semicells were photographed. Microphotographs were taken on an Olympus BX51 light microscope (Olymous, Shinjuku, Japan) with a Bresser MikroCam SP 5.0 digital camera (Bresser, Rhede, Germany). The left lateral lobes of each semicell were used for digitization of landmarks and subsequent analyses. In total, 7 landmarks

(Figs. 1B-C) were depicted on all the specimens using TpsDig software, ver. 2.15 (Rohlf, 2015). In 14 species that exhibited lobe differentiation into $3^{\text {rd }}$-order lobules, an additional 8 landmarks were digitized (Fig. 1B), yielding configurations consisting of 15 landmarks. To assess the measurement error in the analyses of morphological symmetry and asymmetry, all landmarks were digitized twice. In the first digitization, the landmarks were registered from the lower margin of the LLS. In contrast, the landmarks in the second digitization were captured 
243 counterclockwise from the upper ULS margin. Subsequently, the landmarks from the second

244 digitization were relabeled to match the labels of the first digitization (Neustupa, 2017).

\section{Procrustes ANOVA}

247 Four parallel configurations were used for the analysis of object symmetry in individual taxa

248 using a series of Procrustes ANOVA tests. Two lateral sublobes, the LLS and ULS, were

249 compared in two analyses (Fig. 1). The first comprised configurations of 7 landmarks in all 19

250 taxa. Then, all 15 landmarks were used for this analysis in 14 taxa with semicells differentiated

251 into $3^{\text {rd }}$-order lobules (Fig. 1B). In addition, in these 14 taxa, the object symmetry between the

252 opposite terminal lobules within both the LLS (1t11 vs. 1t12) and ULS (ut11 vs. ut12) were also

253 evaluated using the configurations of the 7 landmarks depicted on either of these sublobes (Fig.

254 1B). Thus, Procrustes ANOVA of the object symmetry between two lobules of the LLS was

255 investigated using configurations of landmarks no. 1-7 and the object symmetry within the ULS

256 with landmarks no. 9-15 (Fig. 1B).

257 In all these parallel datasets, the geometric morphometric analysis was based on the

258 generalized Procrustes analysis (GPA) of the two-dimensional landmark coordinates (Zelditch et

259 al. 2012). The resulting Procrustes coordinates were used in the multivariate nonparametric

260 Procrustes ANOVA models to evaluate symmetric variation among individuals, the asymmetric

261 components of positional asymmetry (equivalent to DA) and FA, and the digitization error

262 (Klingenberg et al., 2002; Klingenberg, 2015). The analysis was based on a matrix of tangent

263 Procrustes distances among the original and reflected/relabeled configurations of landmarks.

264 Observed variation was partitioned into several sources, such as the shape differences among the

265 individuals (i.e. different cells); average shape differences between the upper and lower sublobes 
266 within cells, signifying positional asymmetry; the interaction term between these two main

267 effects, denoting FA; and the measurement error, which illustrated the amount of variation

268 spanned by digitization imprecision. The significance of individual effects was evaluated by

269 randomization tests comparing the observed F-values to those obtained by 999 random

270 permutations of the matrix rows comprising the shape data of the specimens (Klingenberg et al., 271 2002).

272 These analyses were conducted using the functions gpagen and bilat.symmetry implemented

273 in the geomorph package, ver. 3.0.5 (Adams \& Otárolla-Castilo, 2013), of R, ver. 3.2 .3 (R

274 Development Core Team, 2016).

275

276 Principal component analysis (PCA) and structure of positional asymmetry

277 While the present study is focused on the patterns of average asymmetry between the lateral

278 lobes and lobules among individual taxa, the overall shape features of these lateral lobes are also

279 considerably different (Neustupa \& Stastny, 2006; Škaloud et al., 2011, Fig. 2). These

280 differences can be expressed as the symmetric variation in the shape of the configurations among

281 the species. Thus, the analysis separated the symmetric variation from the components of

282 bilateral asymmetry. Then, we focused on the asymmetric variation among the configurations

283 depicting the average positional asymmetry of individual taxa. These configurations were

284 yielded by the Procrustes ANOVA models together with their mirrored versions. Therefore,

285 these pairs of asymmetric configurations were obtained for each of the studied taxa. The

286 configurations were merged into a single dataset and subjected to GPA. The Procrustes-aligned

287 coordinates of these original and mirrored average asymmetrical configurations were then

288 subjected to PCA. Resulting principal components (PCs) described either purely symmetric or 
289

290

291

292

293

294

295

296

297

298

299

300

301

302

303

304

305

306

307

308

309

310

311

asymmetric variation with regard to the axis of symmetry dividing the sublobes (Savriama et al., 2010; Savriama \& Klingenberg, 2011). Thus, the asymmetric PCs described the purely

asymmetric shape changes with respect to the axis of bilateral symmetry, showing the patterns of the shape changes in average bilateral asymmetry among the studied taxa. The ideally symmetric configuration with identical sublobes was placed at the center of the ordination space, and the original and mirrored configurations of each specimen were placed at opposite positions on each PC. Differences in any particular configuration from the center of this ordination space explicitly represent the degree and direction of positional asymmetry typical for a given species. In parallel, PCA of the purely asymmetric variation of original configurations, without their mirrored copies, yielded PCs centered at the average asymmetric configuration of all studied taxa. This morphospace was used for mapping the patterns of asymmetry among the taxa onto the phylogeny of the Micrasterias lineage.

PCAs of the aligned configurations were conducted using the function $\operatorname{proc} G P A$ in the shapes package, ver. 1.1-13 (Dryden, 2016), of R, ver. 3.2.3, and in TpsRelw, ver. 1.42 (Rohlf, 2015). This software was also used for reconstruction of the transformation grids depicting shape changes spanned by individual PCs.

\section{Phylogenetic analysis and morphological integration}

The alignment of the 18S rDNA sequences created by Neustupa (2016) consisted of 1641

nucleotides with 116 variable positions. Two separate alignments were used. The first dataset, consisting of 19 Micrasterias species, was related to the morphometric analysis based on 7

landmarks characterizing the shape of the sublobes. The second dataset included 14 species with sublobes differentiated into $3^{\text {rd }}$-order lobules that were used for the morphometric analyses of the 
312 bilateral symmetry between the LLS and ULS based on 15 landmarks as well as for the analyses

313 within these sublobes. The alignments are available at https://doi.org/10.5063/F1GF0RQS.

314 The optimal evolutionary model for the maximum likelihood (ML) analyses was chosen on

315 the basis of the Bayesian information criterion (BIC) implemented by the modeltest function of

316 the phangorn package, ver. 1. 7-4 (Schliep, 2011), in R, ver. 3.2.3. The GTR-G-I model reached

317 the lowest BIC value in both alignments, and consequently, this model was selected for the ML

318 phylogenetic analyses, which were conducted using the functions pml and optim.pml

319 implemented in the phangorn package. Bootstrap supports of the nodes of the phylogenetic trees

320 were calculated by nonparametric bootstrap analysis based on 999 replicates using the

321 bootstrap.pml function of the phangorn package.

322 Two parallel strategies for finding topologies with the lowest parsimony score were used in

323 the maximum parsimony (MP) analyses of both datasets. The optim.parsimony function was

324 used for the nearest-neighbor tree rearrangements, and pratchet was used for the parsimony

325 ratchet searches (Nixon, 1999). Bootstrap analyses of the nodes of the optimal MP phylogenetic

326 tree were based on 999 replicates. Phylogenetic trees were graphically adjusted in FigTree, ver.

327 1.3.1 (Rambaut, 2009).

328 Phylogeny was mapped onto the structure of the shape asymmetry by squared-change

329 parsimony in MorphoJ, ver. 1.06d (Klingenberg, 2011). Then, the evolutionary trajectories were 330 visualized in the shape spaces of individual PCAs. The phylogenetic signal in these shape spaces

331 was evaluated by permutation tests simulating the null hypothesis of the absence of any relation

332 to phylogenetic structure by randomly permuting the shape data among the terminal nodes of the

333 trees and computing the total amount of squared change summed over all branches (Klingenberg

334 \& Gidaszewski, 2010). The tests were based on 9999 random permutations. 
335 Phylogenetic morphological integration between the asymmetric variation at different levels

336 of cellular branching was estimated using the two-block partial least squares (PLS) analysis that

337 also accounted for the phylogeny of the taxa under the Brownian motion model of evolution

338 (Adams \& Felice, 2014).

339 The two-block PLS quantifies covariation between two Procrustes-aligned morphometric

340 datasets by singular value decomposition of the covariance matrix (Zelditch et al., 2012). The

341 resulting axes, which have also been called singular warps, successively describe the shape

342 variation in one dataset with the highest covariation with the second dataset (Bookstein et al.,

343 2003). Linear correlation between the first pair of singular warps has been called the PLS

344 correlation $\left(\mathrm{r}_{\mathrm{PLS}}\right)$ and has been widely used as a measure of morphological integration between

345 two morphological structures (Klingenberg, 2014). In a phylogenetic context, the evolutionary

346 change is modeled by a Brownian motion and is described by an evolutionary covariance matrix

347 yielded by phylogenetic generalized least squares (Adams \& Felice, 2014). The significance of

348 the $\mathrm{r}_{\mathrm{PLS}}$ values between the evolutionary PLS scores from two blocks of the phylogenetically

349 corrected datasets is assessed by comparison to a random distribution of values produced by

350 permutation of species on the tips of the phylogeny in the first dataset in relation to the second

351 dataset. This random distribution was based on 999 replicates.

352 In the present study, phylogenetic morphological integration was evaluated in 14 species with

353 lobes differentiated in the $3^{\text {rd }}$-order lobules. In this dataset, we compared the covariation between

354 the pairs of configurations spanning the asymmetric variation among the species means. Three

355 sets of configurations were considered. The first set consisted of the entire dataset of 15

356 landmarks describing bilateral asymmetry between the LLS and ULS. Then, the landmarks no. 1-

$357 \quad 7$ and 9-15 formed two datasets that described bilateral asymmetry between two terminal lobules 
358 of the LLS and two lobules of the ULS, respectively (Fig. 1B). Thus, three parallel

359 morphological integration analyses were conducted between the pairs of these configurations.

360 The analysis utilized the ML tree produced by the phylogenetic analysis and was conducted

361 using the phylo.integration function implemented in the geomorph package, ver. 3.0.5.

362

\section{Results}

364

365 Two lateral sublobes, namely, the LLS and ULS, were significantly asymmetric in all 19 studied

366 species (Table 1; Table S2). The observed positional asymmetry reached extreme values in $M$.

367 rotata, $M$. compereana, and $M$. fimbriata. In these taxa, positional asymmetry represented the

368 single most important component of the shape variation in the Procrustes ANOVA models,

369 spanning more than $80 \%$ of the total variation between the sublobes (Table 1). This asymmetric

370 pattern largely consisted of a considerably compressed LLS (Figs. 3A-B), which is a well-

371 known morphological feature of these taxa. In addition to these species, LLS was strongly

372 compressed in M. jenneri, M. apiculata and M. papillifera, which was indicated by the negative

373 scores of these taxa on PC1, which encompassed most of the variation in the PCA of the

374 asymmetric shape variation among the original and mirrored mean configurations of the species

375 (Figs. 3A-B). In most remaining species, the amounts of positional asymmetry were

376 considerably lower, but the MS for positional asymmetry still proved to be at least 9 times higher

377 than the MS for FA even in species positioned close to the ideally symmetric midpoint on PC1,

378 such as M. furcata, M. radians var. evoluta, and M. crux-melitensis (Figs. 3A-B; Table S2). In

379 M. semiradiata, M. decemdentata and M. truncata var. pusilla, which occupied the positive parts

380 of the morphospace along the $\mathrm{PC} 1$, the pattern of average asymmetry between the lateral 
381 sublobes was typical by a significantly greater compression of the ULS than that of the LLS (Fig.

$3823 \mathrm{~A})$.

383 The average asymmetry between the two terminal lobules of the LLS was also consistently

384 significant in all 14 taxa possessing $3^{\text {rd }}$-order lobules (Table 1; Table S2). Interestingly,

385 asymmetry between adjacent terminal lobules was generally subtle in taxa with extreme

386 positional asymmetry between the lateral sublobes, such as M. rotata and M. compareana (Table

387 1). On the other hand, several other species, such as M. crux-melitensis and M. denticulata, had

388 pronounced positional asymmetry between the terminal lobules within the LLS or ULS, although

389 their lateral sublobes were much less asymmetric (Table 1; Fig. 3). In M. crux-melitensis and, to

390 a lesser extent, in $M$. fimbriata and several other taxa, the lower-most terminal lobule was

391 considerably more expanded than its adjacent counterpart. In contrast, $M$. denticulata and $M$.

392 thomasiana were typical by distinctly opposite patterns of asymmetry between these lobules

393 (Fig. 3C).

394 The average shape asymmetry between the terminal lobules of the ULS was highly

395 significant in 12 out of the 14 analyzed taxa. In two species, M. furcata and M. radians var.

396 evoluta, the average shapes of these lobules did not differ compared to individual asymmetric

397 deviations (Table 1; Table S2). On the other hand, this type of positional asymmetry was highly

398 pronounced in $M$. brachyptera, a species with rather modest levels of average asymmetry

399 between both the lateral sublobes and the terminal lobules of the LLS. Together with M. rotata

400 and M. crux-melitensis, this species was characteristic by positional asymmetry typified by a

401 significantly large expansion of the upper-most terminal lobule (Fig. 3D). The opposite pattern

402 was only typical for M. semiradiata, which was the only species occupying the negative parts of

$403 \mathrm{PC} 1$ in the morphospace illustrating the asymmetric variation between the terminal lobules of 
404 ULS (Fig. 3D).

405 The ML and MP phylogenetic analyses yielded topologies that were very similar to the

406 previously reported multigenic trees of the Micrasterias lineage (Škaloud et al., 2011; Neustupa

407 et al., 2014). The firmly supported clade "A", including the species complex of $M$. truncata, $M$.

408 furcata (the type species of the genus) and several other taxa, proved to be in a sister position to

409 the remaining clades (Fig. S1). The closely related species $M$. rotata and M. fimbriata formed a

410 joint lineage with $M$. brachyptera and M. compereana, corresponding to clade "B" sensu

411 Škaloud et al. (2011). In addition, M. denticulata, M. jenneri and M. thomasiana also formed a

412 tightly supported clade overlapping with clade "D" of the aforementioned phylogenetic study.

413 Mapping the phylogeny onto the morphospaces showed a strong phylogenetic signal in the

414 among-species patterns of bilateral asymmetry between the LLS and ULS (Figs. 4A-B). The null

415 hypothesis presuming the lack of any phylogenetic signal in both these morphospaces was

416 rejected by the permutation tests with $p=0.0003$ in the 7-landmark dataset and $p=0.0001$ in the

417 dataset based on 15 landmarks. The phylogenetic signal was largely based on the difference in

418 positional asymmetry between the members of clade " $\mathrm{A}$ " and the remaining taxa of the lineage.

419 All the clade "A" taxa had either very similar shapes of ULS and LLS, with only slight positional 420 asymmetry between these sublobes, or their ULS was considerably more compressed than their

421 LLS (Figs. 4A-B). Conversely, members of most other Micrasterias clades showed the opposite 422 pattern of this asymmetry, with significantly compressed LLSs. However, there was a single

423 prominent exception to this scenario. M. americana, which clearly clusters outside of clade "A"

424 in the phylogenetic tree, was positioned close to the members of this clade in the right part of the 425 analyzed morphospace (Fig. 4A). Looking at the morphospace of the original and mirrored

426 configurations, we can see that the LLS of this species was slightly but significantly more 
427 expanded than the ULS (Fig. 3A).

428 The morphospaces describing the patterns of the bilateral asymmetric variation between the

429 adjacent terminal lobules within the LLS and ULS proved to be weakly related to the

430 phylogenetic structure of the lineage (Figs. 4C-D). The null hypothesis was rejected with rather

431 modest values of $p=0.0310$ for the lobules within the LLS and $p=0.0140$ for the ULS.

432 Phylogenetic morphological integration in the among-species asymmetric variation of the

433 terminal lobules within both lateral sublobes was weak and insignificant. The PLS analysis

434 evaluating the degree of covariation while accounting for phylogeny yielded $\mathrm{r}_{\mathrm{PLS}}=0.639$ with $\mathrm{p}$ $435=0.087$. Thus, this analysis did not reject the null hypothesis of total independence between the 436 average asymmetric patterns of the lobules within the LLS and ULS among the analyzed species 437 when their phylogenetic relationships were taken into consideration. Likewise, the average 438 asymmetry between the LLS and ULS was not significantly covariated with the asymmetry of

439 the terminal lobules within the LLS $\left(\mathrm{r}_{\mathrm{PLS}}=0.633, \mathrm{p}=0.121\right)$. Finally, the phylogenetic 440 morphological integration in the asymmetric patterns between the ULS and LLS and those

441 between the lobules within the ULS was weakly significant, with $\mathrm{r}_{\mathrm{PLS}}=0.744$ and $\mathrm{p}=0.021$.

\section{Discussion}

445 Our analyses showed that positional asymmetry is invariably present in the shape of the

446 bilaterally symmetric lateral sublobes of Micrasterias cells, including those taxa that have

447 traditionally been characterized as possessing identical lateral sublobes (Prescott et al., 1977;

448 Růžička, 1981). It has also been shown that this asymmetry is strongly related to phylogenetic

449 history of the lineage. Most infrageneric clades shared the pattern of the LLS being more 
450 compressed than the ULS, which was most pronounced in the species belonging to clade "C",

451 such as M. rotata and M. fimbriata. However, two infrageneric clades were distinctly different.

452 The species-rich clade "A" had either very subtle shape differences between LLS and ULS or

453 there was a pronounced positional asymmetry in the opposite manner to that observed in the rest

454 of the genus. In particular, the subclade that included M. decemdentata, M. semiradiata, and the

455 members of the $M$. truncata species complex was characterized by considerably greater

456 expansion of the LLS than that of the ULS. In addition, there was the peculiar case of $M$.

457 americana, a species that is unrelated to members of clade "A" and forms a clade of its own

458 within the genus, which also shared this pattern of positional asymmetry. It has been shown that

459 M. americana is closely phylogenetically related to the non-European M. mahabuleswarensis, $M$.

460 hardyi and M. muricata (Teiling, 1956; Škaloud et al., 2011). Therefore, it would be interesting

461 to ascertain whether the asymmetry between the sublobes in these taxa is similar to that of $M$.

462 americana, which would indicate that this may be a feature of this entire group, very similar to

463 the scenario observed in members of clade "A". It should be mentioned that the polar lobes in

464 members of clade " $\mathrm{H}$ " are typical by distinct deviations from the front view plane. In $M$.

465 muricata, this pattern of distinctly three dimensional symmetry involves the lateral lobes, too

466 (Holzinger, 2000; Harrison 2011). Thus, this indicates that morphogenetic patterning in this

467 clade differs from most other Micrasterias species, including the species clustering into clade 468 "A".

469 It is unclear which type of positional asymmetry between the LLS and ULS should be

470 considered the ancestral character state within the lineage as a whole. The comprehensive

471 phylogeny of Desmidiaceae, based on the rbcL gene sequences, indicated that clade "A" might

472 be a sister lineage to all other members of the genus (Gontcharov \& Melkonian, 2011), which 
473 was also shown by our $18 \mathrm{~S}$ rDNA phylogenetic analysis. Conversely, the multigene phylogeny

474 described by Škaloud et al. (2011) recovered this clade as a crown lineage, favoring the scenario

475 of the compressed LLS, which is present in most other clades, as a plesiomorphic character.

476 However, weak statistical support for the topology of the deep branches of the Micrasterias

477 phylogeny does not allow any definite conclusions regarding this matter.

478 In any case, the present study has shown that asymmetry between the lateral sublobes of cells 479 constrains the morphological evolution of individual species-level taxa within the clades. In

480 contrast to most other morphological characteristics, the positional asymmetry between LLS and

481 ULS cannot be easily altered during microevolutionary differentiation of these microalgae. This

482 asymmetry has been fixed relatively deep in the evolutionary history of each clade and is shared

483 by all of the members of the clade despite their considerable morphological diversity. In terms of

484 cellular morphogenesis, this result indicates that the position of the minimum accretion zones on

485 developing lateral lobes, which determines the location of the incision between both lateral

486 sublobes (Kiermayer, 1981; Meindl, 1993), is evolutionarily fixed at a level exceeding the

487 boundaries among individual species.

488 Interestingly, the trends in the among-species asymmetric variation between the LLS and

489 ULS were not corroborated by similar analyses at the level of adjacent terminal lobules within

490 the lateral sublobes. The asymmetry in the shapes of the lobules was significant in most taxa, but

491 the patterns of this asymmetry were only marginally related to the phylogenetic structure.

492 Likewise, this among-species asymmetric variation was only weakly integrated with that at the

493 levels of the entire lateral lobes. In addition, phylogenetic morphological integration in

494 asymmetry between the lobules within the LLS and ULS was also insignificant. This result

495 suggests that the asymmetric patterns at the individual hierarchic levels of cellular branching are 
496 almost independent. In other words, individual species may have their own type of evolutionarily

497 fixed positional asymmetry at different levels of bilaterally symmetric structures formed by pairs 498 of the lateral sublobes or the subordinate lobules. These conclusions generally concur with the 499 characteristics of the theoretical reaction-diffusion models of Micrasterias cellular development 500 (Holloway \& Harrison, 1999). These models involve multiple independent centers of tip growth 501 and cell wall patterning, leading to the development of individual sublobes and lobules 502 (Holloway, 2010). Thus, according to the reaction-diffusion models, the growth patterns of cells 503 belonging to different species should be weakly coordinated among different hierarchical levels, 504 which was largely confirmed by the present study. However, it should be noted that these results 505 relate to among-species comparisons of integration. While phylogenetic patterns of average 506 asymmetry among different structures within lateral lobes are relatively independent, shape 507 variation of adjacent lobules within a single population is tightly integrated (Neustupa, 2017).

508 Although it has now been demonstrated that species-level average asymmetry among 509 different lobules is relatively independent, it should be noted that most of the morphological 510 differences among the species are described by their symmetric differences. Therefore, future

511 studies of morphological integration among different parts of Micrasterias cells in the

512 phylogenetic context should also consider the symmetric differences among the configurations

513 typical for individual species. Detection of a significant phylogenetic modularity among the

514 lobes and lobules of different taxa would provide important additional knowledge regarding the

515 phenotypic evolution of Micrasterias. Modularity, typified by minimal developmental

516 coordination (i.e., minimal integration) among the parts of a structure that belong to different

517 evolutionary modules (Klingenberg, 2008), has been known to promote phenotypic

518 diversification among taxa via differential evolutionary rates of morphological change across 
519 units (West-Eberhard, 2003; Larouche et al., 2018). Thus, evolutionary independence among

520 successive lobes and lobules of Micrasterias would be a strong indication that such phylogenetic

521 modularity is a prerequisite for the evolvability of their cellular shapes. This might have been the

522 key feature of Desmidiales leading to their extraordinary morphological diversity, coupled with

523 taxonomic differentiation of more than 2300 extant species and successful colonization of a wide

524 array of freshwater microhabitats. Data on modularity of unicellular organisms are still very

525 scarce but, in the light or our results, it will of special interest to look after the modularity of

526 morphologically complex cells in other microalgal groups, such as Chlorophyceae and the

527 diatoms, to find out if modular arrangement of cells is actually a more general prerequisite for

528 prolific radiation in unicellular eukaryotes.

529 Micrasterias species proved to be intriguing and useful model organisms for the investigation 530 of quantitative morphology and phenotypic plasticity at the cellular level. The flat cells of these

531 species, with straightforward 2D representation of morphological variation and hierarchical

532 differentiation of cellular lobes, provide multiple possibilities for evaluating different scenarios

533 of cellular shape diversification, symmetry and asymmetry, or morphological integration among

534 individual cellular parts (Neustupa \& Stastny, 2006; Neustupa, 2016; Neustupa 2017). The

535 present study primarily focused on the among-species bilaterally asymmetric variation within the

536 lateral lobes. Each of the 1425 analyzed cells was represented by a single lateral lobe, and thus,

537 the intracellular variation among these structures was not evaluated. However, each mature cell

538 includes four lateral lobes (two in each semicell). Therefore, a comprehensive analysis of

539 asymmetry among the sublobes, such as the ULS and LLS, could include an assessment of their

540 variation within the semicells, among the semicells within the cells, and among the cells within

541 populations. Individual components of symmetry and asymmetry, including positional 
542 asymmetry and individual deviations from asymmetric means, could then be partitioned into

543 these hierarchical levels of variation. However, it should be noted that the acquisition of

544 sufficiently large datasets with mature cells represented by four fully developed lateral lobes,

545 especially for a study investigating multiple species, would not be an easy task. Many

546 Micrasterias taxa, such as M. decemdentata, M. fimbriata, M. furcata, and M. jenneri, are rather

547 rare in natural habitats, and acquisition of sufficiently rich natural populations would not be 548 straightforward.

549 The present study focused on the genetically fixed patterns of asymmetry among the species

550 and, thus, primarily compared the amounts and differences in asymmetric means (i.e. positional

551 asymmetry) of the studied structures. Likewise, phylogenetic morphological integration among

552 species has been used to compare species means rather than variation within individual taxa

553 (Adams \& Felice, 2014). Thus, we did not analyze the patterns and amounts of FA within and

554 among the studied populations. However, we can see that these individual asymmetric deviations

555 from the observed positional asymmetry were significant against the digitization error in almost

556 all of the Procrustes ANOVA runs, except for the ULS analysis in M. denticulata, which had

557 unusualy high digitization error (Table S2). In contrast, high FA in shape of M. brachyptera

558 sublobes yielded insignificant test statistic for the differences among the individuals (Table S2).

559 Amounts and patterns of FA have been linked to developmental instability (DI), leading to

560 changes in random asymmetric fluctuations of structures (Palmer \& Strobeck, 2003; Graham et

561 al., 2010; Klingenberg, 2015). Although there may be multiple sources of shape FA in different

562 model systems, a number of studies have shown that DI often increases due to various external

563 factors, such as organic pollution, heavy metals, or suboptimal temperatures (Klingenberg,

564 2015). Interestingly, Micrasterias cells have recently proved to be sensitive indicators for a 
565 number of important stressors, such as heavy metals or increased environmental salinity

566 (Affenzeller et al., 2009; Volland et al., 2011; Andosch et al., 2012; Volland et al., 2014). The

567 heavy metals released to the environment by various anthropogenic activities may often become

568 highly soluble in the acidic conditions of peatland pools, and thus, these metals can pose a real

569 threat to microcommunities inhabiting these habitats. Therefore, geometric morphometric

570 analyses of Micrasterias populations, focusing on FA in shape of the adjacent sublobes might be

571 an intriguing indicator for this kind of environmental stress.

572

573 Conclusions

574

575 This study illustrated probably the most notable morphological feature that closely relates to the

576 phylogenetic history of the Micrasterias lineage. While most previously known morphological

577 characters were poorly correlated to phylogeny, we have shown that breaking of the bilateral

578 symmetry between adjacent lateral sublobes of Micrasterias cells belonging to different species

579 is closely related to their evolutionary relationships. While members of most clades were typical

580 by relatively compressed lower lateral sublobes and comparatively wider upper lateral sublobes,

581 the taxa belonging to the species-rich clade "A" exhibited a phylogenetically conserved pattern

582 with both sublobes characterized by closely similar shapes and only slight levels of positional

583 asymmetry. Interestingly, asymmetric shape patterns between adjacent terminal lobules were

584 largely unrelated to those of the sublobes. Thus, different hierarchical levels of cellular

585 morphology were only weakly coordinated with regard to asymmetric variation among species.

586 This modularity is probably the key to high evolvability of desmid shapes, leading to their

587 extraordinary phenotypic diversity, characterized by more than 2300 extant morphologically 
588 different species.

589

590 Acknowledgments

591 The study was supported by the project "Progres no. Q43" at the Faculty of Science, Charles

592 University, Prague. The authors thank Wiley Editing Services for English language editing and 593 style corrections.

595 References

597 Adams DC, Felice RN. 2014. Assessing trait covariation and morphological integration on 598 phylogenies using evolutionary covariance matrices. Plos ONE 9:e94335 DOI:

$599 \quad$ 10.1371/journal.pone.0094335.

600 Adams DC, Otárola-Castillo E. 2013. geomorph: an R package for the collection and analysis of 601 geometric morphometric shape data. Methods in Ecology and Evolution 4:393-399 DOI: $602 \quad \underline{10.1111 / 2041-210 X .12035 .}$

603 Affenzeller MJ, Darehshouri A, Andosch A, Lütz C, Lütz-Meindl U. 2009. Salt stress-induced 604 cell death in the unicellular green alga Micrasterias denticulata. Journal of Experimental 605 Botany 60:939-954 DOI: 10.1093/jxb/ern348.

606 Andosch A, Affenzeller MJ, Lütz C, Lütz-Meindl U. 2012. A freshwater green alga under 607 cadmium stress: ameliorating calcium effects on ultrastructure and photosynthesis in the 608 unicellular model Micrasterias. Journal of Plant Physiology 169:1489-1500 DOI:

$609 \quad$ 10.1016/j.jplph.2012.06.002. 
610 Bookstein FL, Gunz P, Mitteröcker P, Prossinger H, Schäfer K, Seidler H. 2003. Cranial

611 integration in Homo: singular warps analysis of the midsagittal plane in ontogeny and

612 evolution. Journal of Human Evolution 44:167-187 DOI: 10.1016/S0047-2484(02)00201-4.

613 Coesel PFM, Meesters J. 2007. Desmids of the Lowlands. Zeist: KNNV Publishing.

614 Dryden IL. 2016. Package shapes. R Foundation for Statistical Computing. Contributed package.

615 Version 1.1-13. Available at https://cran.r-project.org/web/packages/shapes/index.html

$616 \quad$ (accessed 8 June 2018).

617 Gontcharov AA, Melkonian M. 2011. A study of conflict between molecular phylogeny and

618 taxonomy in the Desmidiaceae (Streptophyta, Viridiplantae): analyses of $291 \mathrm{rbcL}$

619 sequences. Protist 162:253-267 DOI: 10.1016/j.protis.2010.08.003.

620 Graham JH, Raz S, Hel-Or H, Nevo E. 2010. Fluctuating asymmetry: methods, theory and 621 applications. Symmetry 2:466-540 DOI: 10.3390/sym2020466.

622 Hall JD, Karol KG, McCourt RM, Delwiche CF. 2008. Phylogeny of the conjugating green algae 623 based on chloroplast and mitochondrial nucleotide sequence data. Journal of Phycology 624 44:467-477 DOI: $\underline{10.1111 / \mathrm{j} .1529-8817.2008 .00485 . \mathrm{x}}$.

625 Harrison LG. 2011. The shaping of life: the generation of biological pattern. Cambridge: 626 Cambridge University Press.

627 Holloway DM. 2010. The role of chemical dynamics in plant morphogenesis. Biochemical 628 Society Transactions 38:645-650 DOI: $10.1042 /$ BST0380645.

629 Holloway DM, Harrison LG. 1999. Algal morphogenesis: modelling interspecific variation in 630 Micrasterias with reaction-diffusion patterned catalysis of cell surface growth. Philosophical 631 Transactions of the Royal Society B 354:417-433 DOI: 10.1098/rstb.1999.0395. 
632 Holloway DM, Harrison LG. 2008. Pattern selection in plants: coupling chemical dynamics to

633 surface growth in three dimensions. Annals of Botany 101:361-374 DOI:

$634 \quad \underline{10.1093 / \mathrm{aob} / \mathrm{mcm} 295}$.

635 Holzinger A. 2000. Aspects of cell development in Micrasterias muricata (Desmidiaceae)

636 revealed by cryofixation and freeze substitution. Nova Hedwigia 70:275-288.

637 Holzinger A, Lütz-Meindl U. 2001. Chondramides, novel cyclodepsipeptides from

638 myxobacteria, influence cell development and induce actin filament polymerization in the

639 green alga Micrasterias. Cell Motility and the Cytoskeleton 48:87-95 DOI: 10.1002/1097-

$640 \quad \underline{0169(200102) 48: 2 \% 3 C 87:: A I D-C M 1000 \% 3 E 3.0 . C O ; 2-C .}$

641 Holzinger A, Monajembashi S, Greulich KO, Lütz-Meindl U. 2002. Impairment of cytoskeleton-

642 dependent vesicle and organelle translocation in green algae: combined use of a

643 microfocused infrared laser as microbeam and optical tweezers. Journal of Microscopy

644 208:77-83 DOI: $10.1046 / \mathrm{j} .1365-2818.2002 .01069 . x$.

645 Kiermayer O. 1964. Untersuchungen über die Morphogenese und Zellwandbildung bei

646 Micrasterias denticulata Breb. Protoplasma 59:382-420 DOI: 10.1007/BF01247857.

647 Kiermayer O. 1970. Causal aspects of cytomorphogenesis in Micrasterias. Annals of the New

$648 \quad$ York Academy of Sciences 175:686-701 DOI: 10.1111/j.1749-6632.1970.tb45185.x.

649 Kiermayer O. 1981. Cytoplasmic basis of morphogenesis in Micrasterias. In: Kiermayer O, ed.

650 Cytomorphogenesis in plants. Vienna: Springer Verlag, 147-189.

651 Kiermayer O, Meindl U. 1989. Cellular morphogenesis: the desmid (Chlorophyceae) system. In:

652 Coleman AW, Goff LJ, Stein-Taylor JR, eds. Algae as experimental systems. New York:

653 Alan R. Liss Inc, 149-168. 
654 Klingenberg CP. 2008. Morphological integration and developmental modularity. Annual 655 Reviews of Ecology, Evolution, and Systematics 39:115-132 DOI:

$656 \quad \underline{10.1146 / \text { annurev.ecolsys.37.091305.110054. }}$

657 Klingenberg CP. 2011. MorphoJ: an integrated software package for geometric morphometrics. 658 Molecular Ecology Resources 11:353-357 DOI: 10.1111/j.1755-0998.2010.02924.x.

659 Klingenberg CP. 2014. Studying morphological integration and modularity at multiple levels:

660 concepts and analysis. Philosophical Transactions of the Royal Society B 369:20130249

661 DOI: $10.1098 / \mathrm{rstb} .2013 .0249$.

662 Klingenberg CP. 2015. Analyzing fluctuating asymmetry with geometric morphometrics:

663 concepts, methods, and applications. Symmetry 7:843-934 DOI: 10.3390/sym7020843.

664 Klingenberg CP, Barluenga M, Meyer A. 2002. Shape analysis of symmetric structures:

665 quantifying variation among individuals and asymmetry. Evolution 56:1909-1920 DOI:

$666 \quad \underline{10.1111 / j .0014-3820.2002 . t b 00117 . x .}$

667 Klingenberg CP, Gidaszewski NA. 2010. Testing and quantifying phylogenetic signals and 668 homoplasy in morphometric data. Systematic Biology 59:245-261 DOI:

$669 \quad \underline{10.1093 / \text { sysbio/syp106. }}$.

670 Larouche O, Zelditch ML, Cloutier R. 2018. Modularity promotes morphological divergence in 671 ray-finned fishes. Scientific Reports 8:7278 DOI: 10.1038/s41598-018-25715-y.

672 Lenarczyk J, McManus HA. 2016. Testing the boundaries of the green algal species Pediastrum 673 alternans (Chlorophyceae) using conventional, geometric morphometric and phylogenetic 674 methods. Phycologia 55:515-530 DOI: $\underline{\text { 10.2216/15-129.1. }}$

675 Lütz-Meindl U. 2016. Micrasterias as a model system in plant cell biology. Frontiers in Plant 
677

678

679

680

681

682

683

684

685

686

687

688

689

690

691

692

693

694

695

696

697

McManus HA, Lewis LA, Schultz ET. 2011. Distinguishing multiple lineages of Pediastrum duplex with morphometrics and a proposal for Lacunastrum gen. nov. Journal of Phycology 47:123-130 DOI: $\underline{10.1111 / j .1529-8817.2010 .00941 . x}$.

Meindl U. 1990. Effects of temperature on cytomorphogenesis and ultrastructure of Micrasterias. Protoplasma 157:3-18 DOI: 10.1007/BF01322635.

Meindl U. 1993. Micrasterias cells as a model system for research on morphogenesis. Microbiological Reviews 57:415-433.

Nemjová K, Neustupa J, Stastny J, Škaloud P, Veselá J. 2011. Species concept and morphological differentiation of strains traditionally assigned to Micrasterias truncata. Phycological Research 59:208-220 DOI: 10.1111/j.1440-1835.2011.00619.x.

Neustupa J. 2013. Patterns of symmetric and asymmetric morphological variation in unicellular green microalgae of the genus Micrasterias (Desmidiales, Viridiplantae). Fottea 13:53-63 DOI: $10.5507 /$ fot.2013.005.

Neustupa J. 2016. Static allometry of unicellular green algae: scaling of cellular surface area and volume in the genus Micrasterias (Desmidiales). Journal of Evolutionary Biology 29:292305 DOI: $10.1111 /$ jeb.12781.

Neustupa J. 2017. Asymmetry and integration of cellular morphology in Micrasterias compereana. BMC Evolutionary Biology 17:1 DOI: 10.1186/s12862-016-0855-1.

Neustupa J, Stastny J. 2006. The geometric morphometric study of Central European species of the genus Micrasterias (Zygnematophyceae, Viridiplantae). Preslia 78:253-263.

Neustupa J, Stastny J, Hodač L. 2008. Temperature-related phenotypic plasticity in the green 
698 microalga Micrasterias rotata. Aquatic Microbial Ecology 51:77-86 DOI:

$699 \quad \underline{10.3354 / \mathrm{ame} 01184 .}$

700 Neustupa J, Stastny J, Škaloud P. 2014. Splitting of Micrasterias fimbriata (Desmidiales,

701 Viridiplantae) into two monophyletic species and description of Micrasterias compereana sp.

702 nov. Plant Ecology and Evolution 147:405-411 DOI: 10.5091/plecevo.2014.991.

703 Nixon K. 1999. The parsimony ratchet, a new method for rapid parsimony analysis. Cladistics

704 15:407-414 DOI: 10.1111/j.1096-0031.1999.tb00277.x.

705 Palmer AR, Strobeck C. 2003. Fluctuating asymmetry analyses revisited. In: Polak M, ed.

706 Developmental instability: causes and consequences. Oxford: Oxford University Press, 279$707 \quad 319$.

708 Poulíčková A, Mazalová P, Vašut RJ, Šarhanová P, Neustupa J, Škaloud P. 2014. DNA content

709 variation and its significance in the evolution of the genus Micrasterias (Desmidiales,

710 Streptophyta). Plos ONE 9:e86247 DOI: 10.1371/journal.pone.0086247.

711 Prescott GW, Croasdale HT, Vinyard WC. 1977. A synopsis of North American desmids, Part II.

712 Desmidiaceae: Placodermae, Sect. 2. Lincoln: University of Nebraska Press.

713 R Development Core Team 2016. R: A language and environment for statistical computing.

714 Available at https://cran.r-project.org/bin/windows/base/old/3.2.3/ (accessed 8 June 2018).

715 Rambaut A. 2009. Figtree, tree figure drawing tool, version 1.3.1. Available at

716 http://tree.bio.ed.ac.uk/software/figtree/ (accessed 8 June 2018).

717 Rohlf FJ. 2015. The tps series of software. Hystrix Italian Journal of Mammalogy 26:9-12 DOI:

$718 \quad 10.4404 /$ hystrix-26.1-11264.

719 Růžička J. 1981. Die Desmidiaceen Mitteleuropas, Band 1, 2. Lieferung. Stuttgart: 
Schweizerbart Verlag.

721 Savriama Y, Gerber S, Baiocco M, Debat V, Fusco G. 2017. Development and evolution of

722 segmentation assessed by geometric morphometrics: The centipede Strigamia maritima as a

723 case study. Arthropod Structure \& Development 46:419-428 DOI:

$724 \quad$ https://doi.org/10.1016/j.asd.2017.03.002.

725 Savriama Y, Klingenberg CP. 2011. Beyond bilateral symmetry: geometric morphometric

726 methods for any type of symmetry. BMC Evolutionary Biology 11:280 DOI: 10.1186/1471-

$727 \quad 2148-11-280$.

728 Savriama Y, Neustupa J, Klingenberg CP. 2010. Geometric morphometrics of symmetry and

729 allometry in Micrasterias rotata (Zygnematophyceae, Viridiplantae). Nova Hedwigia

$730 \quad$ Beihefte 136:43-54.

731 Schliep KP. 2011. phangorn: phylogenetic analysis in R. Bioinformatics 27:592-593 DOI:

732 10.1093/bioinformatics/btq706.

733 Škaloud P, Nemjová K, Veselá J, Černá K, Neustupa J. 2011. A multilocus phylogeny of the

734 desmid genus Micrasterias (Streptophyta): evidence for the accelerated rate of morphological

735 evolution in protists. Molecular Phylogenetics and Evolution 61:933-943 DOI:

$736 \quad \underline{10.1016 / j . y m p e v .2011 .08 .018}$.

737 Teiling E. 1956. On the variation of Micrasterias mahabuleshwarensis f. Wallichii. Botaniska

$738 \quad$ Notiser 109:260-274.

739 Vannerum K, Huysman MJJ, De Rycke R, Vuylsteke M, Leliaert F, Pollier J, Lütz-Meindl U,

740 Gillard J, De Veylder L, Goossens A, Inzé D, Vyverman W. 2011. Transcriptional analysis of

741 cell growth and morphogenesis in the unicellular green alga Micrasterias (Streptophyta), 
742 with emphasis on the role of expansin. BMC Plant Biology 11:128 DOI: 10.1186/1471-2229-

$743 \underline{11-128 .}$.

744 Volland S, Andosch A, Milla M, Stöger B, Lütz C, Lütz-Meindl U. 2011. Intracellular metal

745 compartmentalization in the green algal model system Micrasterias denticulata

746 (Streptophyta) measured by transmission electron microscopy-coupled electron energy loss

747 spectroscopy. Journal of Phycology 47:565-579 DOI: 10.1111/j.1529-8817.2011.00988.x.

748 Volland S, Bayer E, Baumgartner V, Andosch A, Lütz C, Sima E, Lütz-Meindl U. 2014. Rescue

749 of heavy metal effects on cell physiology of the algal model system Micrasterias by

750 divalentions. Journal of Plant Physiology 171:154-163 DOI: $\underline{10.1016 / j . j p l p h .2013 .10 .002 .}$

751 West-Eberhard MJ. 2003. Developmental plasticity and evolution. Oxford: Oxford University

752 Press.

753 Zelditch ML, Swiderski DL, Sheets DH. 2012. Geometric morphometrics for biologists: a

754 primer. London: Elsevier Academic Press.

755 


\section{Table $\mathbf{1}$ (on next page)}

The mean squares (MS), percentages of variance $\left(R^{2}\right)$ and $p$-values of positional asymmetry in individual Procrustes ANOVA analyses of bilateral symmetry.

The abbreviations identify structures depicted in Figure 1. 


\begin{tabular}{|c|c|c|c|c|c|c|c|c|c|c|c|c|}
\hline \multirow[t]{2}{*}{ Species } & \multicolumn{3}{|c|}{$\begin{array}{l}\text { LLS vs. ULS } \\
\quad(7 \text { LM) }\end{array}$} & \multicolumn{3}{|c|}{$\begin{array}{l}\text { LLS vs. ULS } \\
\quad(15 \text { LM) }\end{array}$} & \multicolumn{3}{|c|}{$\begin{array}{l}\text { Itl1 vs. ltl2 } \\
\text { (7 LM) }\end{array}$} & \multicolumn{3}{|c|}{$\begin{array}{l}\text { utl1 vs. utl2 } \\
\text { (7 LM) }\end{array}$} \\
\hline & MS & $\mathbf{R}^{2}$ & $p$ & MS & $\mathbf{R}^{2}$ & $p$ & MS & $\mathbf{R}^{2}$ & $p$ & MS & $\mathbf{R}^{2}$ & $p$ \\
\hline M. americana & 0.044 & 0.044 & 0.001 & $\mathrm{X}$ & $\mathrm{X}$ & $\mathrm{X}$ & $\mathrm{X}$ & $\mathrm{X}$ & $\mathrm{X}$ & $\mathrm{X}$ & $\mathrm{X}$ & $X$ \\
\hline M apiculata & 0.745 & 0.638 & 0.001 & 0.532 & 0.574 & 0.001 & 0.705 & 0.469 & 0.001 & 0.158 & 0.178 & 0.001 \\
\hline M. brachyptera & 0.189 & 0.122 & 0.001 & 0.131 & 0.099 & 0.001 & 0.113 & 0.040 & 0.001 & 0.540 & 0.182 & 0.001 \\
\hline M. crux-melitensis & 0.043 & 0.056 & 0.001 & 0.055 & 0.075 & 0.001 & 2.029 & 0.637 & 0.001 & 0.562 & 0.289 & 0.001 \\
\hline M. compereana & 2.959 & 0.848 & 0.001 & 1.973 & 0.806 & 0.001 & 0.113 & 0.087 & 0.001 & 0.120 & 0.132 & 0.001 \\
\hline M. decemdentata & 0.881 & 0.440 & 0.001 & $\mathrm{X}$ & $\mathrm{X}$ & $\mathrm{X}$ & $\mathrm{X}$ & $\mathrm{X}$ & $\mathrm{X}$ & $\mathrm{X}$ & $\mathrm{X}$ & $\mathrm{X}$ \\
\hline M. denticulata & 0.528 & 0.497 & 0.001 & 0.355 & 0.445 & 0.001 & 0.721 & 0.480 & 0.001 & 0.246 & 0.260 & 0.001 \\
\hline M. fimbriata & 3.406 & 0.839 & 0.001 & 2.439 & 0.811 & 0.001 & 0.956 & 0.396 & 0.001 & 0.240 & 0.227 & 0.001 \\
\hline M. furcata & 0.077 & 0.049 & 0.001 & 0.068 & 0.046 & 0.001 & 0.027 & 0.015 & 0.002 & 0.007 & 0.004 & 0.146 \\
\hline M. jenneri & 1.703 & 0.761 & 0.001 & $\mathrm{X}$ & $\mathrm{X}$ & $\mathrm{X}$ & $\mathrm{X}$ & $\mathrm{X}$ & $\mathrm{X}$ & $\mathrm{X}$ & $\mathrm{X}$ & $\mathrm{X}$ \\
\hline M. papillifera & 0.606 & 0.511 & 0.001 & 0.445 & 0.442 & 0.001 & 0.069 & 0.054 & 0.001 & 0.350 & 0.255 & 0.001 \\
\hline M. radians var. bogoriensis & 0.023 & 0.015 & 0.001 & 0.037 & 0.028 & 0.001 & 0.084 & 0.032 & 0.001 & 0.188 & 0.061 & 0.001 \\
\hline M. radians var. evoluta & 0.036 & 0.023 & 0.001 & 0.031 & 0.024 & 0.001 & 0.085 & 0.038 & 0.001 & 0.003 & 0.001 & 0.469 \\
\hline M. rotata & 4.303 & 0.878 & 0.001 & 3.017 & 0.828 & 0.001 & 0.022 & 0.016 & 0.001 & 0.675 & 0.379 & 0.001 \\
\hline M. semiradiata & 0.600 & 0.406 & 0.001 & 0.387 & 0.321 & 0.001 & 0.402 & 0.195 & 0.001 & 0.286 & 0.103 & 0.001 \\
\hline M. thomasiana & 0.252 & 0.421 & 0.001 & 0.176 & 0.376 & 0.001 & 0.373 & 0.416 & 0.001 & 0.025 & 0.052 & 0.001 \\
\hline M. truncata var. pusilla & 1.582 & 0.448 & 0.001 & $\mathrm{X}$ & $\mathrm{X}$ & $\mathrm{X}$ & $\mathrm{X}$ & $\mathrm{X}$ & $\mathrm{X}$ & $\mathrm{X}$ & $\mathrm{X}$ & $\mathrm{X}$ \\
\hline M. truncata var. quadrata & 0.140 & 0.224 & 0.001 & $\mathrm{X}$ & $\mathrm{X}$ & $\mathrm{X}$ & $\mathrm{X}$ & $\mathrm{X}$ & $\mathrm{X}$ & $\mathrm{X}$ & $\mathrm{X}$ & $\mathrm{X}$ \\
\hline M. truncata var. truncata & 0.182 & 0.228 & 0.001 & 0.125 & 0.157 & 0.001 & 0.562 & 0.295 & 0.001 & 0.070 & 0.039 & 0.001 \\
\hline
\end{tabular}




\section{Figure 1 (on next page)}

Morphology of Micrasterias cells.

(A) The mature cell of $M$. radians var. evoluta with two semicells, each including two lateral lobes (LL1-LL4). Red line depicts the axis of symmetry between two opposite semicells. Blue line depicts the symmetry axis between two halves of each semicell. (B) The lateral lobe of M. crux-melitensis with the lower (LLS) and upper (ULS) lateral sublobes, each composed of two $3^{\text {rd }}$-order terminal lobules ( $|t| 1,|t| 2$, ut 1 , ut|2). The positions of 7 landmarks depicting the sublobes are shown by red circles, and an additional 8 landmarks depicting the terminal lobules are shown in ligth blue. The orange line depicts the axis of symmetry between two adjacent lateral sublobes. (C) The lateral lobe of $M$. truncata var. pusilla with two sublobes (LLS, ULS). The positions of 7 landmarks depict the lateral sublobes. The orange line depicts the axis of symmetry between two adjacent lateral sublobes. 


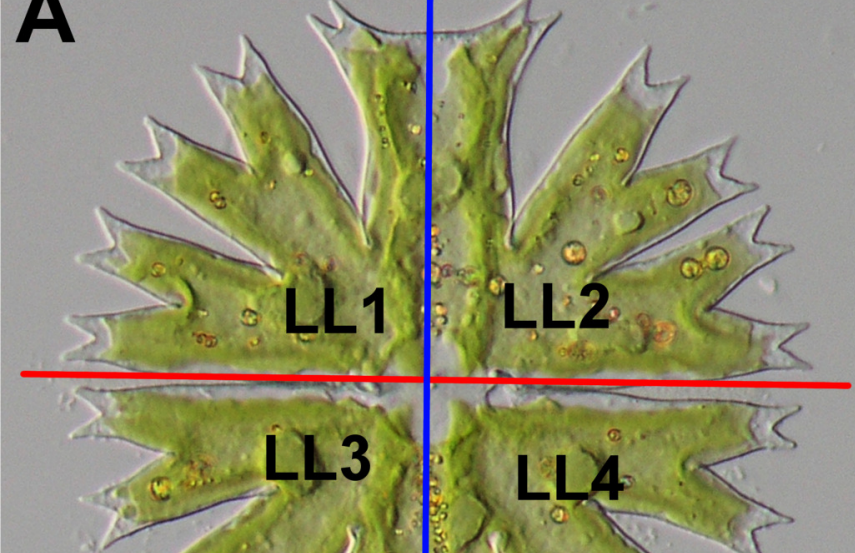
6. $5 \quad[13$

LL4

$139(2) \cdot(2)$

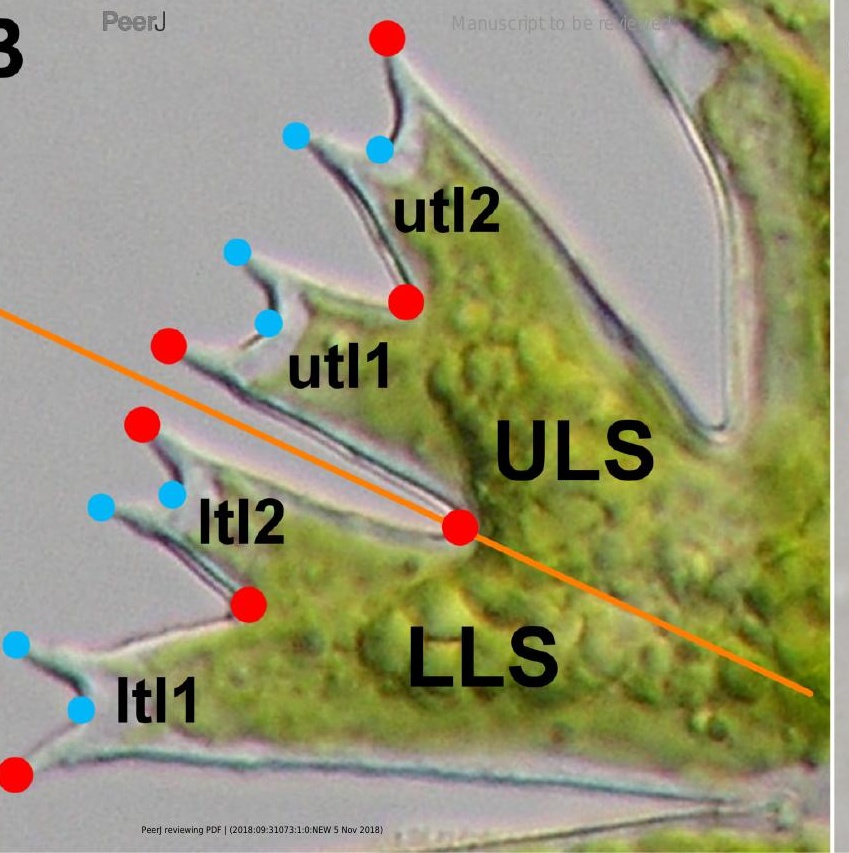

C

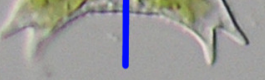

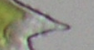

त

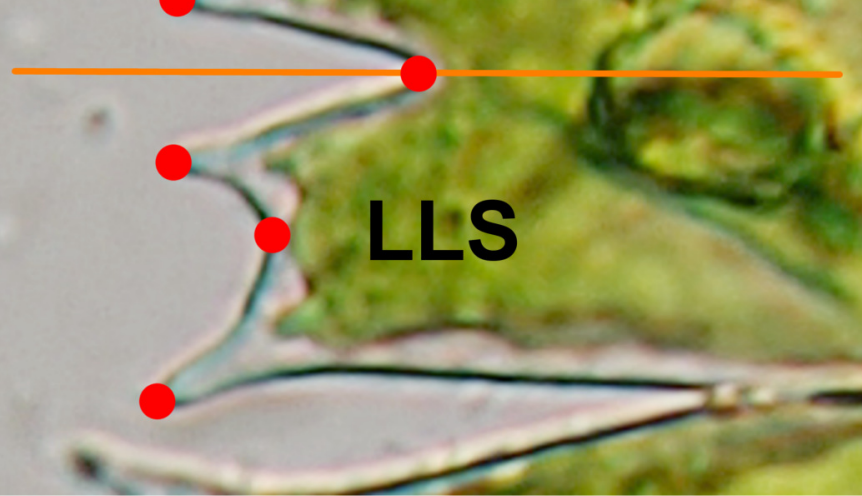




\section{Figure 2}

Semicells of 19 Micrasterias taxa.

(A) M. americana. (B) M. apiculata. (C) M. brachyptera. (D) M. crux-melitensis. (E) M. compereana. (F) M. decemdentata. (G) M. denticulata. (H) M. fimbriata. (I) M. furcata. (J) M. jenneri. (K) M. papillifera. (L) M. radians var. bogoriensis. (M) M. radians var. evoluta. (N) M. rotata. (O) M. semiradiata. (P) M. thomasiana. (Q) M. thomasiana. (R) M. truncata var. pusilla. (S) M. truncata var. quadrata. (T) M. truncata var. truncata. Scale bars $=12 \mu \mathrm{m}(\mathrm{F}, \mathrm{R}-\mathrm{T}), 20$ $\mu m(D, J, K, O), 25 \mu m(A, I, L, M)$, and $30 \mu m(B, C, E, G, H, N, P, Q)$.

*Note: Auto Gamma Correction was used for the image. This only affects the reviewing manuscript. See original source image if needed for review. 


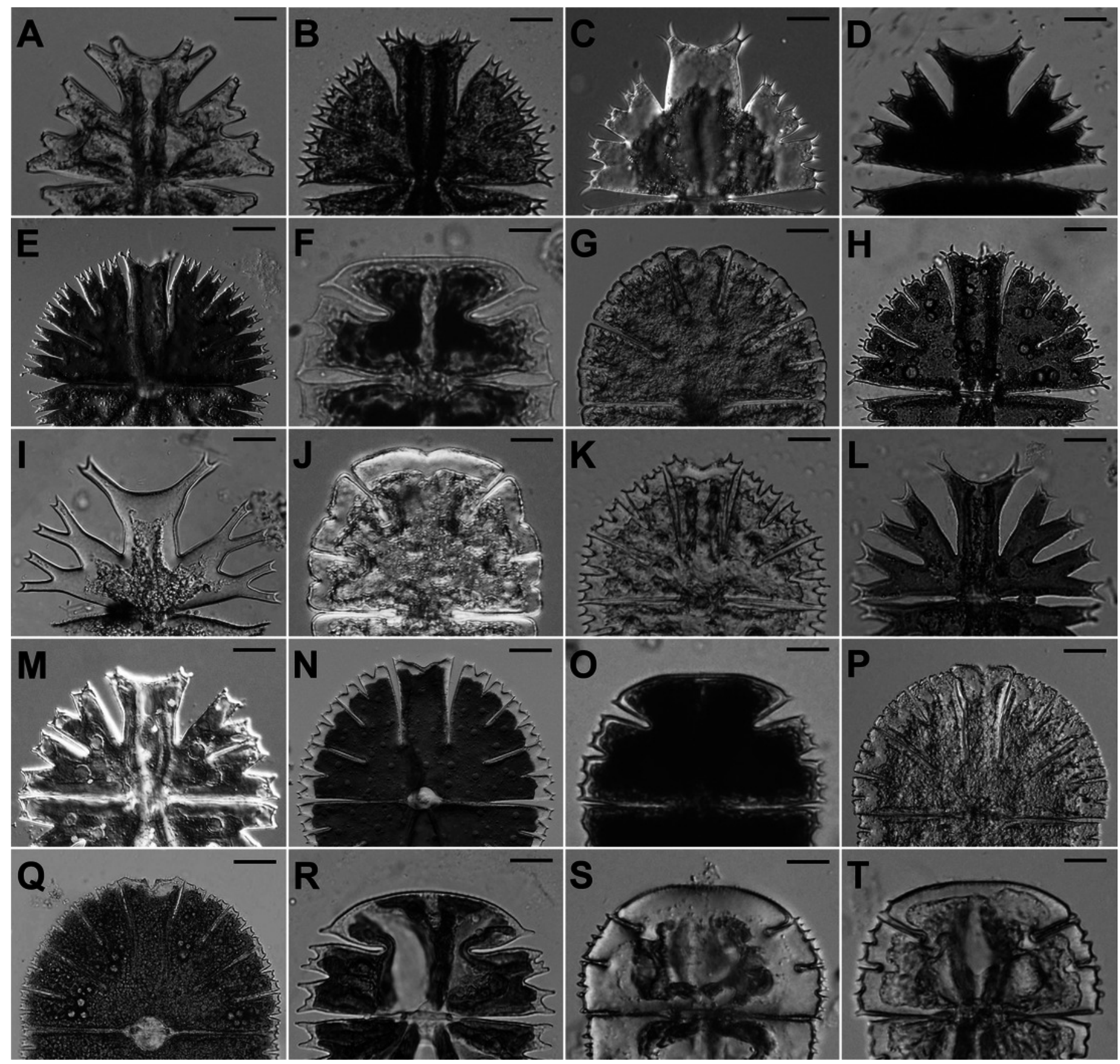




\section{Figure 3 (on next page)}

PCA ordination plots showing the differences in positional asymmetry of the adjacent lateral sublobes.

The red dots depict the position of the original asymmetric configurations for each species. The gray dots show their mirrored copies. Deformation grids illustrate the ideally symmetric configuration (located at the midpoint of each plot) and the configurations typical for $3 \times$ S.D. positions on both extremes of PC1. The schemes in the upper left corners show the types of bilateral asymmetry illustrated by each particular analysis. Abbreviations of taxa correspond to those in Table S1. (A) Positional asymmetry between the LLS and ULS based on configurations of 7 landmarks. (B) Positional asymmetry between the LLS and ULS based on configurations of 15 landmarks. (C) Positional asymmetry patterns between the two terminal lobules within the LLS. (D) Positional asymmetry patterns between the two terminal lobules within the ULS. 


\section{Figure 4 (on next page)}

Micrasterias phylogeny mapped onto the morphospaces represented by the PC1 vs. PC2 ordination plots based on the patterns of positional asymmetry within the species.

Deformation grids illustrate the configuration of the asymmetric grand mean and those typical for $3 \times$ S.D. positions on both extremes of PC1. The schemes in the upper left corners show the types of bilateral asymmetry illustrated by each particular analysis. Abbreviations of taxa correspond to those in Table S1. Members of the monophyletic clade "A", firmly supported in the phylogenetic analysis, are depicted by green circles. (A) PCA based on the positional asymmetry between the LLS and ULS registered by the configurations of 7 landmarks. (B) PCA based on the positional asymmetry between the LLS and ULS registered by the configurations of 15 landmarks. (C) PCA of the positional asymmetry patterns between the two terminal lobules within the LLS. (D) PCA of the positional asymmetry patterns between the two terminal lobules within the ULS. 
